Research Article

\title{
Modeling and Estimation of Grinding Forces for Mono Layer cBN Grinding Wheel
}

\author{
Chithajalu Kiran Sagar ${ }^{\dot{A^{*}}}$ and Bhaskar Pal ${ }^{\dot{\mathrm{B}}}$ \\ ${ }^{\dot{A}}$ Department of Mechanical Engineering Dayananda Sagar Academy of Technology \& Management, Bangalore, Karnataka, India \\ Mechanical Engineering Department \\ ${ }^{\dot{B}}$ Alliance College of Engineering and Design Alliance University, Chandapura - Anekal Main Road, Anekal, Bangalore, Karnataka, India
}

Accepted 17 January 2014, Available online 01 February 2014, Special Issue-2, (February 2014)

\begin{abstract}
This paper shows a new grinding force model which was developed by incorporating the effects of tangential, normal and variable coefficient of friction force. This was based on the fact that chip formation during grinding consists of three stages: plowing, cutting and rubbing. Equations for the total normal and tangential force components per unit width of the grinding, during cutting and rubbing (friction) were established. These components were expressed in terms of the experimental coefficients and process parameters like wheel speed, table feed and depth of cut. All the coefficients were determined by considering experimental data of previous work which has been conducted on single layer brazed cBN wheel. The variation of the friction coefficient with process parameters such as wheel speed and work feed were taken into consideration while calculating the frictional force components. The predicted normal and tangential grinding forces were compared with those experimentally obtained data. The results showed reasonably good agreement with experimental data. From the total force values the contributions of each component of force were obtained. It was observed minutely that total calculated forces were bit lesser than the experimented data. This variation was due to the plowing force which was not considered in the force model.
\end{abstract}

Keywords: Grinding force model, Brazed single layer $c B N$ wheel.

\section{Introduction}

Grinding is the common collective name for machining processes which utilize hard abrasive particles as the cutting medium(Malkin.S et al 2008). Grinding is a complex material removal process with a large number of parameters influencing each other. In the process, the grinding wheel surface contacts the work piece at high speed and under high pressure. The complexity of the process lies in the multiple microscopic interaction modes in the wheel-work piece contact zone, including cutting, plowing, sliding, chip/work piece friction, chip/bond friction, and bond/work piece friction. This becomes extremely complicated when comes to precise quantitative evaluation for the process performance due to the lack of perception in the wheel-work piece contact zone(Peters et al 1984). The perception of grinding process from the micro-level advances the understanding of grinding mechanism. Since the microscopic modes are intimately related with the process performance, the quantification of microscopic modes could definitely enhance the troubleshooting in grinding processes. The microscopic cutting and plowing are the major enablers for grinding force, and also contribute to the abrasive grain wear(Torrance.A 2005). The grain wear, chip formation

*Corresponding author: Chithajalu Kiran Sagar

DOI: http://dx.doi.org/10.14741/ijcet/spl.2.2014.15

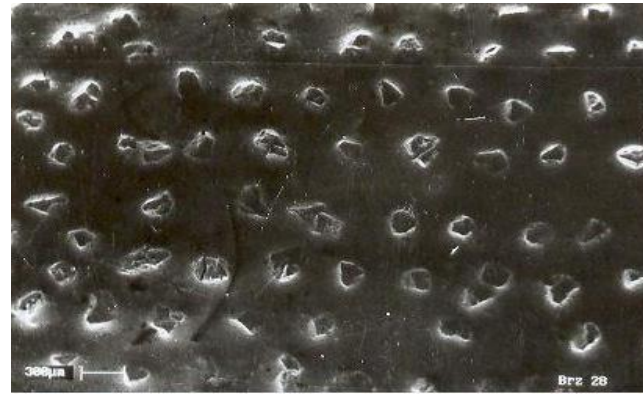

(a)

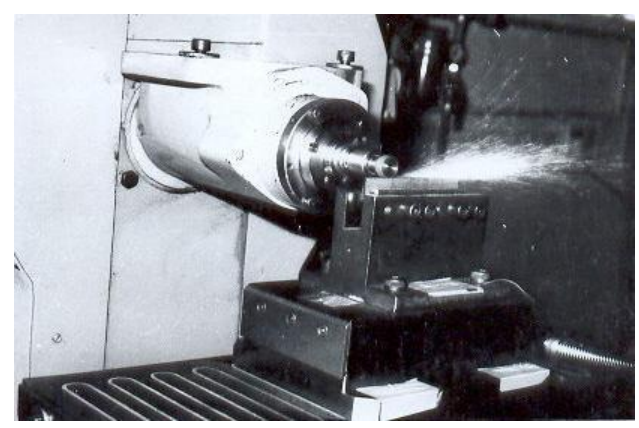

(b)

Figure 1 (a) SEM photograph of wheel topography after brazing, (b) Experimental force measurement during grinding bearing steel with single layer wheel.

78 | International Conference on Advances in Mechanical Sciences 2014 
by an active grain, and localized force could result in the wheel surface condition alteration in terms of wear flat (Guo.C 1999), loading and grain or bond breakage respectively. The material removal by the grains and localized heat generated there on could result the work piece surface topography and metallurgical change(Ju.Y et al 1998). And microscopic cutting as well as its integration would influence the actual depth of grinding considering that the grinding system is not perfectly rigid(Saini.D.P. et al 1985)(Wager.J.G. et al 1986)(Brown.R.H et al 1971). From this perspective, this research work has been carried out for modeling and analyzing the grinding forces on monolayer $\mathrm{cBN}$ brazed wheel. These wheels have manufactured by brazing process. The $15 \mathrm{~mm}$ diameter steel shank has been considered for the wheel. The cBN grits of $181 \mu \mathrm{m}$ were uniformly distributed on the periphery of steel shank with the help of $\mathrm{Ag}-\mathrm{Cu}-\mathrm{Ti}$ active brazing alloy. Then the wheel was kept in the vacuum furnace for brazing purpose. The temperature was maintained at $7800 \mathrm{C}$ and the pressure 10-3torr (Bhaskar Pal et al 2010)(Li Lichun et al1980)(M.Younis et al 1987).

\section{Grinding Force Model}

Grinding forces can be separated into two parts, cutting deformation force and frictional force. The cutting deformation force is again sub-divided into plowing force and cutting or chip formation force.

$\mathbf{F}=\mathbf{F}_{\text {plow }}+\mathbf{F}_{\text {chip }}+\mathbf{F}_{\text {friction }}$

The effect of plowing is neglected as the grit being considered to be a single point tool. So the plowing effect will be very low in comparison with the chip formation force. Hence general equation for grinding force written as $\mathbf{F}=\mathbf{F}_{\text {chip }}+\mathbf{F}_{\text {friction }}$

$\mathbf{F}_{\mathbf{n}}^{\prime}=\mathbf{F}_{\mathbf{n c}}^{\prime}+\mathbf{F}_{\mathbf{n r}}^{\prime}$

$\mathbf{F}_{n}^{\prime}=$ normal grinding force per unit width of grinding, $\mathrm{N} / \mathrm{mm}$

$\mathbf{F}^{\prime}{ }_{\mathbf{n c}}=$ normal component of chip formation force per unit width of grinding, $\mathrm{N} / \mathrm{mm}$

$\mathbf{F}^{\prime}{ }_{\text {nr }}=$ normal component of frictional force per unit width of grinding, $\mathrm{N} / \mathrm{mm}$

$\mathbf{F}_{\mathrm{t}}^{\prime}=\mathbf{F}_{\mathrm{tc}}^{\prime}+\mathbf{F}_{\mathrm{tr}}^{\prime}$

$\mathbf{F}_{\mathbf{t}}=$ tangential grinding force per unit width of grinding, $\mathrm{N} / \mathrm{mm}$

$\mathbf{F}^{\prime}{ }_{\mathbf{t c}}=$ tangential component of chip formation force per unit width of grinding, $\mathrm{N} / \mathrm{mm}$

$\mathbf{F}^{\prime}{ }_{\mathbf{t r}}=$ tangential component of the frictional force per unit width of grinding, $\mathrm{N} / \mathrm{mm}$

\section{Chip formation force components}

In developing the chip formation force components the cutting action of a single grain of the grinding wheel is assumed to be similar to the action of a single point cutting tool in turning. Hence the normal component of chip formation force imposed by a single grain can be determined as a function of undeformed chip crosssectional area, which can be written as

$\mathbf{F}_{\text {enc }}=K_{\mathbf{i}}$

$\mathbf{F}_{\text {enc }}=$ normal chip formation force component of a single grain, $\mathrm{N}$
$\mathbf{Q}_{\mathrm{i}}=$ chip cross-sectional area, $\mathrm{mm}^{2}$

$\mathbf{K}=$ chip thickness co-efficient, $\mathrm{N} / \mathrm{mm}^{2}$

The total normal chip formation force per unit width of the grinding is the total of the normal forces of all active grains within the contact area of wheel and work piece:

$\mathbf{F}_{\mathbf{n c}}^{\prime}=\sum \mathbf{K} \mathbf{Q}_{\mathbf{i}}=\mathbf{K} \sum \mathbf{Q}_{\mathbf{i}}$

$\sum \mathbf{Q}_{\mathbf{i}}$ is the total value of all simultaneous chip crosssections per unit width of grinding and is given as $[15,16]$

$\sum \mathbf{Q}_{\mathbf{i}}=\frac{\mathbf{v}_{\mathbf{w}}}{\mathbf{v}_{\mathbf{c}}} \mathbf{a}$

$\mathbf{F}_{\mathbf{n c}}^{\prime}=\mathbf{K} \frac{\mathbf{V}_{\mathbf{w}}}{\mathbf{v}_{\mathbf{c}}} \mathbf{a}$

$\mathbf{a}=$ depth of cut, $\mathrm{mm}$

$\mathbf{V}_{\mathbf{c}}=$ wheel speed, $\mathrm{mm} / \mathrm{s}$

$\mathbf{V}_{\mathbf{w}}=$ work piece feed or table speed, $\mathrm{mm} / \mathrm{s}$

In the case of pure chip formation, the ratio of tangential force component to normal force component of a single grain bears a ratio $\psi$ that is dependent on the profile of the grains of the grinding wheel [15]:

$\frac{\mathrm{F}_{\text {etc }}}{\mathrm{F}_{\text {enc }}}=\boldsymbol{\Psi}$

Where $\psi=\frac{\Pi}{\tan \theta}$

$\mathbf{F}_{\text {etc }}=$ tangential chip formation force component of a single grain, $\mathrm{N}$

Similar to the normal force component, the total tangential chip formation force component per unit width of the grinding can be determined as [15]

$\mathbf{F}_{\mathbf{t c}}^{\prime}=\sum \boldsymbol{\Psi} \mathbf{F}_{\mathbf{e n c}}=\psi \mathrm{K} \sum \mathbf{Q}_{\mathbf{i}}=\psi \mathrm{K} \frac{\mathbf{V}_{\mathbf{w}}}{\mathbf{V}_{\mathbf{c}}} \mathbf{a}$

$\mathbf{F}_{\mathbf{t c}}^{\prime}=\mathbf{K}^{\prime} \frac{\mathbf{V}_{\mathbf{w}}}{\mathbf{V}_{\mathbf{c}}} \mathbf{a}$

$\mathbf{K}^{\prime}=\boldsymbol{\psi} \mathbf{K}$

$\mathbf{K}^{\prime}=$ experimental co-efficient, $\mathrm{N} / \mathrm{mm}^{2}$

Where $\mathbf{K}, \mathbf{K}^{\prime}$ are the chip thickness coefficients, which are determined through experiments.

\section{Frictional force components}

The rubbing phenomenon in grinding is because of the flat area of the grinding wheel, which is caused by the wear of the grains. Experiments prove that the normal force of each grain will vary directly with the wear area. Hence the normal and tangential frictional force components of a single grain are

$\mathbf{F}_{\text {enr }}=\boldsymbol{\delta} \overline{\mathbf{p}}$

$\mathbf{F}_{\text {enr }}=$ normal frictional force component of a single grain, $\mathrm{N}$

$\mathbf{F}_{\text {etr }}=\mathbf{F}_{\mathrm{enr}} \boldsymbol{\mu}=\boldsymbol{\mu} \boldsymbol{\delta} \overline{\mathbf{p}}$

$\mathbf{F}_{\text {etr }}=$ tangential frictional force component of a single grain, $\mathrm{N}$

Where, $\boldsymbol{\mu}$ is the coefficient of friction, $\boldsymbol{\delta}$ the tip area of the worn grain and $\overline{\mathbf{p}}$ the average contact pressure between the wheel and the work piece.

Hence the total normal and tangential frictional force components are

$\mathbf{F}_{\mathbf{n r}}=\propto_{\mathbf{n}} \overline{\mathbf{p}}=(\mathbf{N} \boldsymbol{\delta}) \overline{\mathbf{p}}$

$\mathbf{F}_{\mathbf{n r}}=$ normal component of frictional force, $\mathrm{N}$

$\mathbf{F}_{\text {tr }}=\boldsymbol{\mu} \propto_{\mathbf{n}} \overline{\mathbf{p}}=\boldsymbol{\mu}(\mathbf{N} \boldsymbol{\delta}) \overline{\mathbf{p}}$

$\mathbf{F}_{\mathrm{tr}}=$ tangential component of the frictional force, $\mathrm{N}$

$\propto_{\mathbf{n}}=\mathbf{b l}_{\mathbf{c}} \mathbf{A}=\mathbf{N} \boldsymbol{\delta}$ 
Table 1 The parameters/levels considered for experimentation to determine the chip formation and frictional force model coefficients

\begin{tabular}{|c|c|c|c|c|}
\hline Parameters/levels & Wheel diameter (m) & Depth of cut $\quad(m)$ & Work feed $(\mathrm{m} / \mathrm{min})$ & $\begin{array}{l}\text { Wheel speed } \\
(\mathrm{m} / \mathrm{sec})\end{array}$ \\
\hline 1 & .0153 & $\begin{array}{l}10 e^{-6} \\
20 e^{-6} \\
30 e^{-6}\end{array}$ & 2 & $\begin{array}{l}16 \\
20 \\
27.5 \\
35 \\
41\end{array}$ \\
\hline 2 & .0153 & $\begin{array}{l}10 e^{-6} \\
20 e^{-6} \\
30 e^{-6}\end{array}$ & 3 & $\begin{array}{l}16 \\
20 \\
27.5 \\
35 \\
41\end{array}$ \\
\hline 3 & .0153 & $\begin{array}{l}10 e^{-6} \\
20 e^{-6} \\
30 e^{-6}\end{array}$ & 4 & $\begin{array}{l}16 \\
20 \\
27.5 \\
35 \\
41\end{array}$ \\
\hline
\end{tabular}

Table 2 Experimental coefficients of chip formation and frictional force components

\begin{tabular}{|l|l|l|l|l|}
\hline $\mathrm{K}$ & \multicolumn{1}{|c|}{$K^{\prime}$} & $K_{1}$ & \multicolumn{1}{|c|}{$K_{2}$} & $K_{3}$ \\
\hline 47664567.41 & 34016446.08 & 56757.91 & 2803.94 & 4385.89 \\
\hline
\end{tabular}

$l_{c}=d_{e}\left(d_{e} a\right)^{1 / 2}$

$\mathbf{b}=$ width of the grinding, $\mathrm{mm}$

$\mathbf{d}_{\mathbf{e}}=\quad$ equivalent

diameter,

$\mathrm{mm}$

$\mathbf{l}_{\mathbf{c}}=$ geometric contact length, $\mathrm{mm}$

Where, $\propto_{\mathbf{n}}$ is the real contact area between the wheel and the work piece. A the fraction of the wheel surface that has worn flat. $\mathbf{N}$ is the total number of active grains which can be counted from the Fig.1.Using the parabola function to approximate the cutting path, the deviation $(\Delta)$ between the grinding wheel radius $\left(\mathbf{d}_{\mathbf{s}} / \mathbf{2}\right)$ and the radius of curvature of cutting path $(\mathbf{R})$ is

$$
\begin{aligned}
& \Delta=\frac{2}{d_{s}}-\frac{1}{R} \\
& \Delta= \pm \frac{4 V_{w}}{v_{c} d_{e}}
\end{aligned}
$$

The average contact pressure $\overline{\mathbf{p}}$ between the work piece and the wear plane of the abrasive grains increases approximately linearly with the deviation $(\Delta)$ of the radius of curvature and this relationship is given by.

$\overline{\mathbf{p}}=\mathbf{p}_{0} \Delta=\frac{4 \mathbf{p}_{0} V_{\mathrm{w}}}{\mathbf{d}_{\mathrm{e}} \mathrm{V}_{\mathrm{c}}}$

$\mathbf{P}_{\mathbf{o}}=$ proportionality constant, $\mathrm{N} / \mathrm{mm}$

The average contact pressure $(\overline{\mathbf{p}})$ varies with the processing parameters of grinding. Therefore most likely there exists an elastic contact, elasto-plastic contact or plastic contact. Hence the frictional coefficient $\boldsymbol{\mu}$ also varies with the average contact pressure. According to the frictional binomial theorem, the variable frictional coefficient is given by the formula.

$\boldsymbol{\mu}=\frac{\alpha_{0} \mathbf{A}_{\mathbf{0}}}{\mathrm{w}}+\boldsymbol{\beta}=\propto_{\mathbf{0}} \overline{\mathbf{p}}+\boldsymbol{\beta}$

$\mathbf{W}=$ normal load on the work piece, $\mathrm{N}$

$\boldsymbol{\alpha}_{\mathbf{0}}=$ experimental co-efficient, $\mathrm{N} / \mathrm{mm}^{2}$

$\boldsymbol{\beta}=$ experimental co-efficient, $\mathrm{N} / \mathrm{mm}^{2}$
Where $\propto_{\mathbf{0}}$ and $\boldsymbol{\beta}$ are the coefficients, which are dependent on the physical and mechanical properties of the contact interface.

Substituting Equations (14), (15), (18) and (19) into Equations (12) and (13), the total tangential and normal frictional force components per unit width of grinding $\mathbf{F}_{\text {tr }}^{\prime}$ and $\mathbf{F}_{\mathbf{n r}}^{\prime}$ are obtained as

$\mathbf{F}_{\text {tr }}^{\prime}=\left(\propto_{0} \overline{\mathbf{p}}+\boldsymbol{\beta}\right) \overline{\mathbf{p}} \mathbf{b}\left(\mathbf{d}_{\mathrm{e}} \mathbf{a}\right)^{1 / 2} \mathbf{A}$

$F_{\text {tr }}^{\prime}=\left(\propto_{0}+\beta \bar{p}\right) b\left(d_{e} a\right)^{1 / 2} A$

$F_{\text {tr }}^{\prime}=\left(A \propto_{0}+\frac{4 A p_{0} \beta V_{w}}{d_{e} V_{c}}\right)\left(d_{e} a\right)^{1 / 2}$

$F_{\text {tr }}^{\prime}=\left(K_{2}+\frac{K_{3} V_{w}}{d_{e} V_{c}}\right)\left(d_{e} a\right)^{1 / 2}$

$K_{2}=A \propto_{0}, K_{3}=4 A p_{0} \beta$

$F_{n r}=\frac{4 p_{0} V_{w}}{d_{e} V_{c}} b\left(d_{e} a\right)^{1 / 2} A$

$F_{n r}^{\prime}=\frac{4 A p_{0} V_{w}}{V_{c}}\left(\frac{a}{d_{e}}\right)^{1 / 2}$

$F_{n r}^{\prime}=\frac{K_{1} V_{w}}{V_{c}}\left(\frac{a}{d_{e}}\right)^{1 / 2}$

$K_{1}=\mathbf{4 A P _ { 0 }}$

$\mathbf{K}_{\mathbf{1}}=$ experimental co-efficient, $\mathrm{N} / \mathrm{mm}$

$\mathbf{K}_{\mathbf{2}}=$ experimental co-efficient, $\mathrm{N} / \mathrm{mm}^{2}$

$\mathbf{K}_{\mathbf{3}}=$ experimental co-efficient, $\mathrm{N} / \mathrm{mm}$

Where $\mathbf{K}_{\mathbf{1}}, \mathbf{K}_{\mathbf{2}}, \mathbf{K}_{\mathbf{3}}$ are coefficients, which depend on the wheel and work piece combination and are determined through experiments.

\section{Final grinding force equations}

Substituting equations (7), (9), (23), and (26) in equations. (2) and (3), the final equations for normal and tangential grinding force per unit width of grinding are

$F_{n}^{\prime}=K \frac{V_{w}}{V_{c}} a+\frac{K_{1} V_{w}}{V_{c}}\left(\frac{a}{d_{e}}\right)^{1 / 2}$

$F_{t}^{\prime}=K^{\prime} \cdot \frac{V_{w}}{V_{c}} a+\left(K_{2}+\frac{k_{3} V_{w}}{d_{e} V_{c}}\right)\left(\operatorname{ad}_{e}\right)^{1 / 2}$ 
Table 3 Cutting and frictional component of normal and Tangential force for different wheel speed Normal force calculation

Work feed $2 \mathrm{~m} / \mathrm{min}$

\begin{tabular}{|l|l|l|l|l|l|l|l|l|l|}
\hline $\begin{array}{l}V_{c} \\
\mathrm{~m} / \mathrm{s}\end{array}$ & \multicolumn{2}{|l|}{$\begin{array}{l}\mathrm{F}_{\mathrm{nc}}^{\prime} \\
\mathrm{N} / \mathrm{mm}\end{array}$} & \multicolumn{3}{c|}{$\mathrm{N} / \mathrm{mm}$} & \multicolumn{3}{c|}{$\mathrm{N} / \mathrm{mm}$} \\
\hline & $\begin{array}{l}10 \\
\text { micron }\end{array}$ & $\begin{array}{l}20 \\
\text { micron }\end{array}$ & $\begin{array}{l}30 \\
\text { micron }\end{array}$ & 10 micron & 20 micron & 30 micron & $\begin{array}{l}10 \\
\text { micron }\end{array}$ & $\begin{array}{l}20 \\
\text { micron }\end{array}$ & $\begin{array}{l}30 \\
\text { micron }\end{array}$ \\
\hline 16 & .09 & 1.99 & 2.98 & 3.02 & 4.27 & 5.23 & 4.02 & 6.26 & 8.22 \\
\hline 20 & .79 & 1.59 & 2.38 & 2.41 & 3.42 & 4.18 & 3.21 & 5.01 & 6.57 \\
\hline 27.5 & .57 & 1.16 & 1.73 & 1.75 & 2.48 & 3.04 & 2.34 & 3.64 & 4.78 \\
\hline 35 & .45 & .908 & 1.36 & 1.38 & 1.95 & 2.39 & 1.84 & 2.86 & 3.76 \\
\hline 41 & .38 & .775 & 1.16 & 1.17 & 1.66 & 2.04 & 1.57 & 2.44 & 3.21 \\
\hline
\end{tabular}

Work feed $3 \mathrm{~m} / \mathrm{min}$

\begin{tabular}{|l|l|l|l|l|l|l|l|l|l|}
\hline $\begin{array}{l}V_{c} \\
\mathrm{~m} / \mathrm{s}\end{array}$ & \multicolumn{2}{|l}{$\begin{array}{l}\mathrm{F}_{\mathrm{nc}}^{\prime} \\
\mathrm{N} / \mathrm{mm}\end{array}$} & \multicolumn{3}{c|}{$\mathrm{N} / \mathrm{mm}$} & \multicolumn{3}{c|}{$\mathrm{F} / \mathrm{mm}$} \\
\hline & $\begin{array}{l}10 \\
\text { micron }\end{array}$ & $\begin{array}{l}20 \\
\text { micron }\end{array}$ & $\begin{array}{l}30 \\
\text { micron }\end{array}$ & 10 micron & 20 micron & 30 micron & $\begin{array}{l}10 \\
\text { micron }\end{array}$ & $\begin{array}{l}20 \\
\text { micron }\end{array}$ & $\begin{array}{l}30 \\
\text { micron }\end{array}$ \\
\hline 16 & 1.49 & 2.98 & 4.47 & 4.53 & 6.41 & 7.85 & 6.02 & 9.39 & 12.3 \\
\hline 20 & 1.19 & 2.38 & 3.57 & 3.62 & 5.13 & 6.28 & 4.82 & 7.51 & 9.86 \\
\hline 27.5 & .86 & 1.73 & 2.60 & 2.63 & 3.73 & 4.56 & 3.5 & 5.46 & 7.17 \\
\hline 35 & .68 & 1.36 & 2.04 & 2.07 & 2.93 & 3.59 & 2.75 & 4.29 & 5.63 \\
\hline 41 & .58 & 1.16 & 1.74 & 1.76 & 2.50 & 3.06 & 2.35 & 3.67 & 4.81 \\
\hline
\end{tabular}

Work feed $4 \mathrm{~m} / \mathrm{min}$

\begin{tabular}{|l|l|l|l|l|l|l|l|l|l|}
\hline $\begin{array}{l}V_{c} \\
\mathrm{~m} / \mathrm{s}\end{array}$ & \multicolumn{3}{|l|}{$\begin{array}{l}\mathrm{F}_{\mathrm{nc}}^{\prime} \\
\mathrm{N} / \mathrm{mm}\end{array}$} & \multicolumn{3}{c|}{$\mathrm{N} / \mathrm{mm}$} & \multicolumn{3}{c|}{$\mathrm{N} / \mathrm{mm}$} \\
\hline & $\begin{array}{l}10 \\
\text { micron }\end{array}$ & $\begin{array}{l}20 \\
\text { micron }\end{array}$ & $\begin{array}{l}30 \\
\text { micron }\end{array}$ & 10 micron & 20 micron & 30 micron & $\begin{array}{l}10 \\
\text { micron }\end{array}$ & $\begin{array}{l}20 \\
\text { micron }\end{array}$ & $\begin{array}{l}30 \\
\text { micron }\end{array}$ \\
\hline 16 & 1.99 & 3.97 & 5.96 & 6.04 & 8.55 & 10.47 & 8.03 & 12.5 & 16.4 \\
\hline 20 & 1.59 & 3.18 & 4.77 & 4.83 & 6.84 & 8.37 & 6.43 & 10 & 13.1 \\
\hline 27.5 & 1.16 & 2.31 & 3.47 & 3.51 & 4.97 & 6.09 & 4.67 & 7.29 & 9.56 \\
\hline 35 & 0.90 & 1.82 & 2.72 & 2.86 & 3.90 & 4.78 & 3.67 & 5.72 & 7.51 \\
\hline 41 & 0.77 & 1.55 & 2.33 & 2.35 & 3.33 & 4.08 & 3.13 & 4.89 & 6.41 \\
\hline
\end{tabular}

Tangential force calculation

Work feed $2 \mathrm{~m} / \mathrm{min}$

\begin{tabular}{|l|l|l|l|l|l|l|l|l|l|}
\hline $\begin{array}{r}V_{c} \\
\mathrm{~m} / \mathrm{s}\end{array}$ & \multicolumn{2}{|l|}{$\begin{array}{l}\mathrm{F}_{\mathrm{tc}}^{\prime} \\
\mathrm{N} / \mathrm{mm}\end{array}$} & \multicolumn{3}{c|}{$\mathrm{N} / \mathrm{mm}$} & \multicolumn{3}{c|}{$\mathrm{N} / \mathrm{mm}$} \\
\hline & $\begin{array}{l}10 \\
\text { micron }\end{array}$ & $\begin{array}{l}20 \\
\text { micron }\end{array}$ & $\begin{array}{l}30 \\
\text { micron }\end{array}$ & 10 micron & $\begin{array}{l}20 \\
\text { micron }\end{array}$ & 30 micron & $\begin{array}{l}10 \\
\text { micron }\end{array}$ & $\begin{array}{l}20 \\
\text { micron }\end{array}$ & 30 micron \\
\hline 16 & 0.70 & 1.42 & 2.13 & 1.33 & 1.88 & 2.30 & 2.04 & 3.30 & 4.43 \\
\hline 20 & 0.56 & 1.13 & 1.70 & 1.28 & 1.81 & 2.22 & 1.85 & 2.95 & 3.92 \\
\hline 27.5 & 0.41 & 0.82 & 1.24 & 1.23 & 1.74 & 2.13 & 1.65 & 2.57 & 3.37 \\
\hline 35 & 0.32 & 0.64 & 0.97 & 1.20 & 1.70 & 2.08 & 1.53 & 2.35 & 3.06 \\
\hline 41 & 0.27 & 0.55 & 0.83 & 1.18 & 1.67 & 2.05 & 1.46 & 2.23 & 2.89 \\
\hline
\end{tabular}

Work feed $3 \mathrm{~m} / \mathrm{min}$

\begin{tabular}{|l|l|l|l|l|l|l|l|l|l|}
\hline $\begin{array}{l}V_{c} \\
\mathrm{~m} / \mathrm{s}\end{array}$ & \multicolumn{3}{|l|}{$\mathrm{F}_{\mathrm{tc}}^{\prime}$} & \multicolumn{3}{c|}{$\mathrm{F} / \mathrm{Fm}$} & \multicolumn{3}{c|}{$\mathrm{N} / \mathrm{mm}$} \\
\hline & $\begin{array}{l}\mathrm{N} / \mathrm{mm} \\
\text { micron }\end{array}$ & $\begin{array}{l}20 \\
\text { micron }\end{array}$ & $\begin{array}{l}30 \\
\text { micron }\end{array}$ & $\begin{array}{l}10 \\
\text { micron }\end{array}$ & 20 micron & 30 micron & $\begin{array}{l}10 \\
\text { micron }\end{array}$ & $\begin{array}{l}20 \\
\text { micron }\end{array}$ & 30 micron \\
\hline 16 & 1.06 & 2.13 & 3.19 & 1.44 & 2.04 & 2.50 & 2.51 & 4.17 & 5.7 \\
\hline 20 & 0.85 & 1.70 & 2.55 & 1.37 & 1.94 & 2.38 & 2.23 & 3.65 & 4.94 \\
\hline 27.5 & 0.61 & 1.24 & 1.86 & 1.30 & 1.83 & 2.25 & 1.92 & 6.08 & 4.11 \\
\hline 35 & 0.48 & 0.97 & 1.46 & 1.25 & 1.77 & 2.17 & 1.74 & 2.75 & 3.63 \\
\hline 41 & 0.41 & 0.83 & 1.24 & 1.23 & 1.74 & 2.13 & 1.65 & 2.57 & 3.38 \\
\hline
\end{tabular}


Work feed $4 \mathrm{~m} / \mathrm{min}$

\begin{tabular}{|l|l|l|l|l|l|l|l|l|l|}
\hline $\begin{array}{c}V_{c} \\
\mathrm{~m} / \mathrm{s}\end{array}$ & $\begin{array}{l}\text { F } \\
\text { Ftc } \\
\mathrm{N} / \mathrm{mm}\end{array}$ & \multicolumn{3}{c|}{$\mathrm{N} / \mathrm{mm}$} & \multicolumn{3}{c|}{$\mathrm{F}_{\mathrm{tr}}^{\prime}$} & $\mathrm{N} / \mathrm{mm}$ \\
\hline & $\begin{array}{l}10 \\
\text { micron }\end{array}$ & $\begin{array}{l}20 \\
\text { micron }\end{array}$ & $\begin{array}{l}30 \\
\text { micron }\end{array}$ & 10 micron & 20 micron & 30 micron & 10 micron & $\begin{array}{l}20 \\
\text { micron }\end{array}$ & $\begin{array}{l}30 \\
\text { micron }\end{array}$ \\
\hline 16 & 1.42 & 2.83 & 4.25 & 1.56 & 2.21 & 2.70 & 2.98 & 5.05 & 6.96 \\
\hline 20 & 1.13 & 2.27 & 3.40 & 1.47 & 2.07 & 2.54 & 2.6 & 4.35 & 5.95 \\
\hline 27.5 & 0.82 & 1.65 & 2.47 & 1.36 & 1.93 & 2.37 & 2.19 & 3.58 & 4.84 \\
\hline 35 & 0.64 & 1.30 & 1.94 & 1.31 & 1.85 & 2.26 & 1.96 & 3.15 & 4.21 \\
\hline 41 & 0.55 & 1.11 & 1.66 & 1.27 & 1.80 & 2.21 & 1.83 & 2.92 & 3.87 \\
\hline
\end{tabular}

Table 4: Experimental values

Normal Forces

\begin{tabular}{|l|l|l|l|l|l|l|l|l|l|}
\hline $\begin{array}{c}V_{c} \\
\mathrm{~m} / \mathrm{s}\end{array}$ & \multicolumn{3}{|l|}{ Work feed $2 \mathrm{~m} / \mathrm{min}$} & \multicolumn{3}{l|}{ Work feed 3 m/min } & \multicolumn{3}{l|}{ Work feed $4 \mathrm{~m} / \mathrm{min}$} \\
\hline & $10 \mu$ & $20 \mu$ & $30 \mu$ & $10 \mu$ & $20 \mu$ & $30 \mu$ & $10 \mu$ & $20 \mu$ & $30 \mu$ \\
\hline 16 & 5 & 7.82 & 9 & 5.5 & 9.6 & 11.4 & 6.74 & 10.54 & 13.12 \\
\hline 20 & 3.98 & 6.8 & 7.25 & 4.42 & 8.22 & 8.2 & 6.1 & 9.55 & 12 \\
\hline 27.5 & 3 & 5 & 6.2 & 3.13 & 6.625 & 7 & 4.38 & 7.82 & 10.8 \\
\hline 35 & 2.7 & 4.145 & 4.465 & 2.6 & 5.38 & 5.4 & 3.6 & 5.75 & 9.5 \\
\hline 41 & 2.67 & 4.26 & 4 & 2 & 5 & 4.8 & 3.67 & 5 & 8.24 \\
\hline
\end{tabular}

Tangential Forces

\begin{tabular}{|l|l|l|l|l|l|l|l|l|l|}
\hline $\begin{array}{c}V_{c} \\
\mathrm{~m} / \mathrm{s}\end{array}$ & \multicolumn{3}{|l|}{ Work feed 2 $\mathrm{m} / \mathrm{min}$} & \multicolumn{3}{l|}{ Work feed 3 m/min } & \multicolumn{3}{l|}{ Work feed 4 m/min } \\
\hline & $10 \mu$ & $20 \mu$ & $30 \mu$ & $10 \mu$ & $20 \mu$ & $30 \mu$ & $10 \mu$ & $20 \mu$ & $30 \mu$ \\
\hline 16 & 3.22 & 5 & 6.18 & 3.9 & 5.45 & 6.5 & 3.28 & 5.23 & 5.585 \\
\hline 20 & 2.5 & 3.5 & 5.22 & 2.8 & 4.21 & 5.3 & 2.525 & 3.73 & 4.95 \\
\hline 27.5 & 2.1 & 2.8 & 3.5 & 2.1 & 3.21 & 3.5 & 2.1 & 3 & 4.25 \\
\hline 35 & 1.53 & 1.95 & 2.65 & 1.61 & 2.26 & 2.98 & 1.75 & 2.56 & 3.845 \\
\hline 41 & 1.25 & 1.81 & 2 & 1.1 & 2 & 2.5 & 1.5 & 2.2 & 3.5 \\
\hline
\end{tabular}

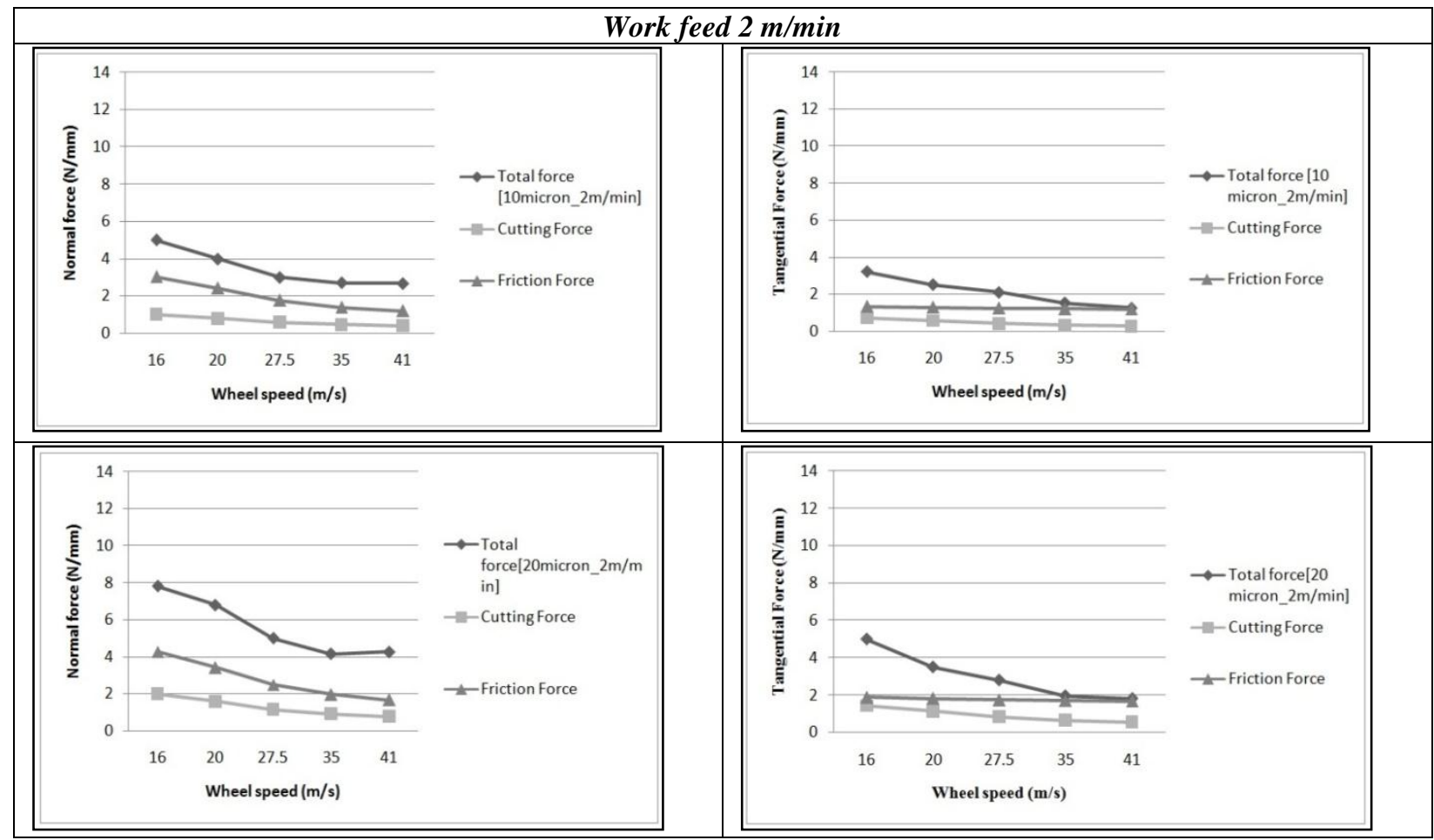




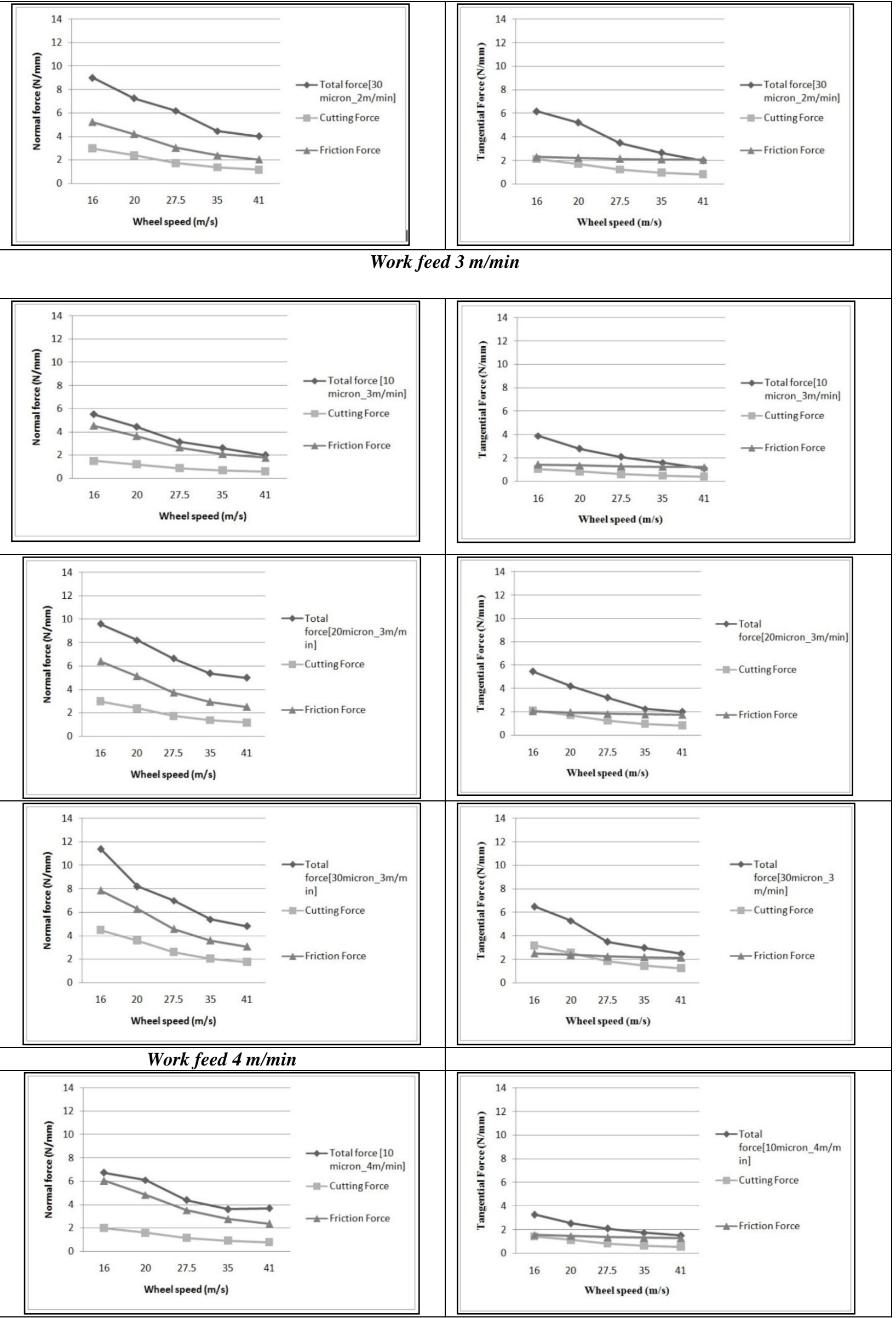

83 International Conference on Advances in Mechanical Sciences 2014 

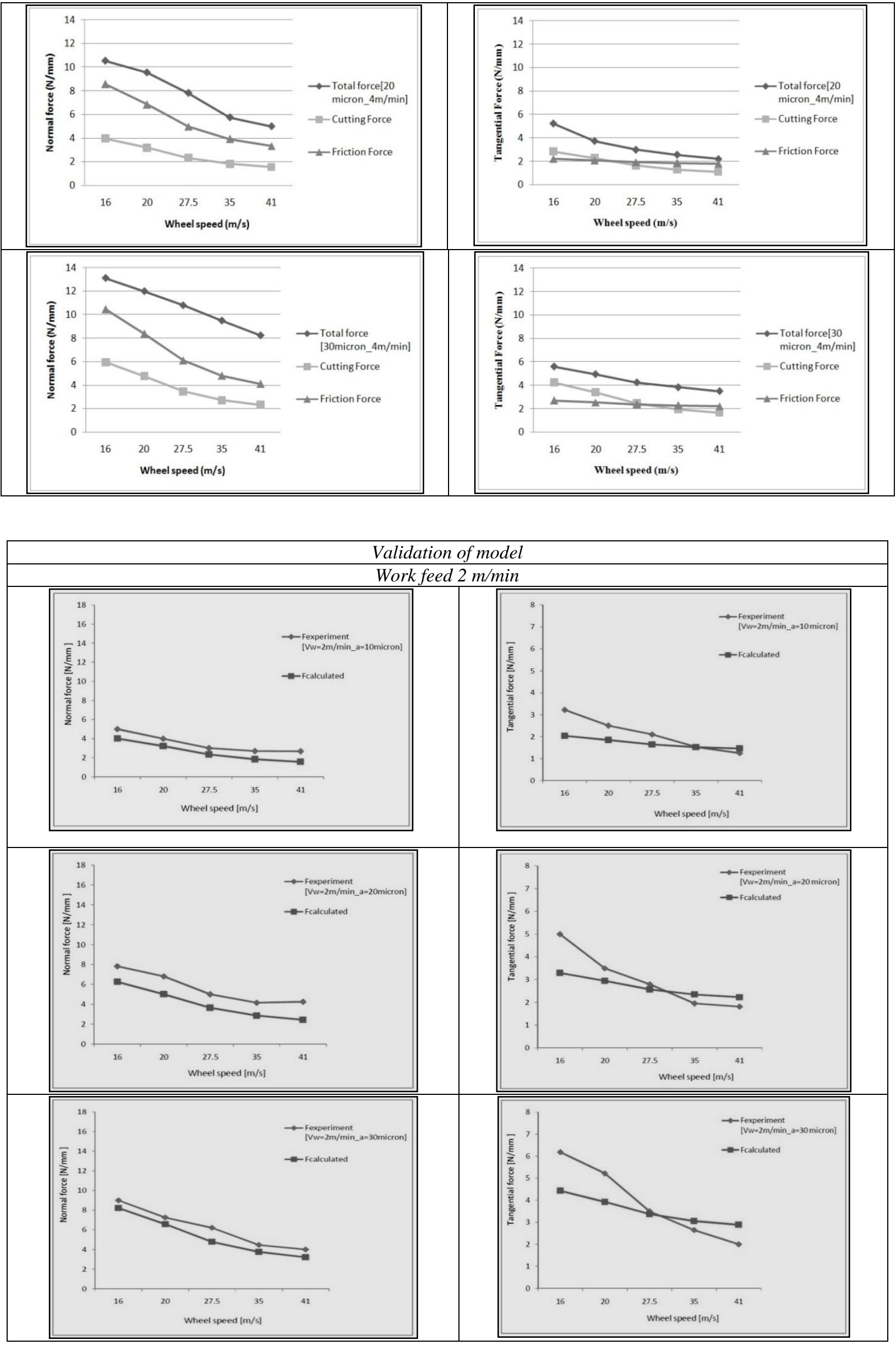


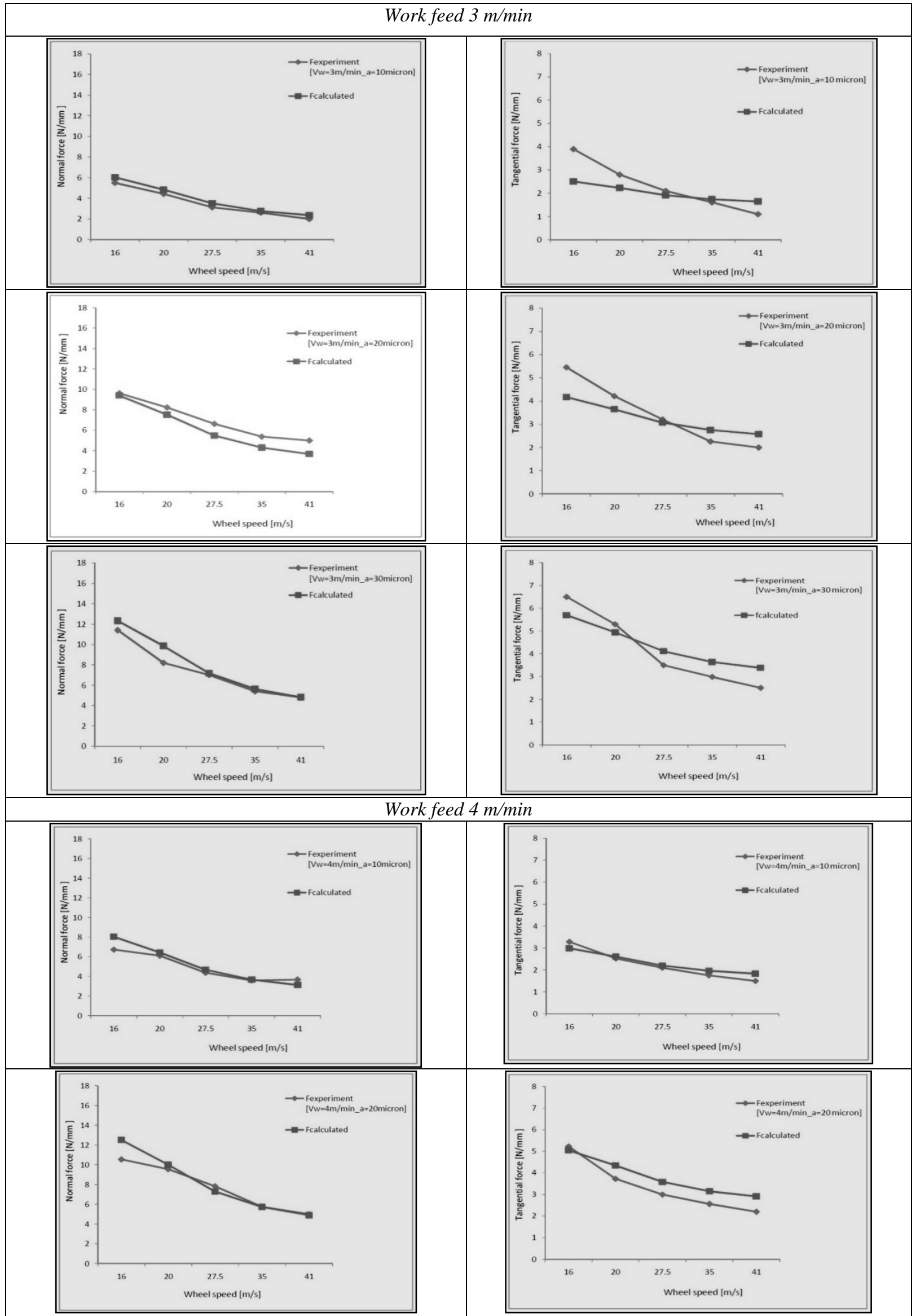




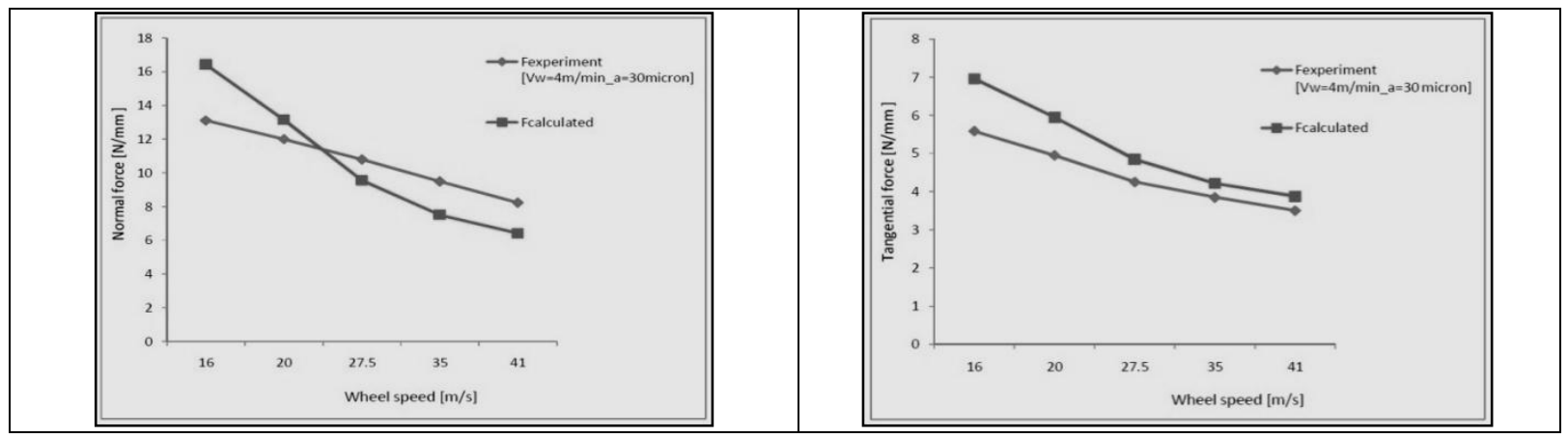

Grinding Force Calculation

\section{Chip formation force and frictional force coefficients}

The finalize equations for normal and tangential grinding force per unit width of grinding are shown in equations (27) and (28) respectively. The five coefficients $\boldsymbol{K}, \boldsymbol{K}^{\prime}, \boldsymbol{K}_{\mathbf{1}}, \boldsymbol{K}_{\mathbf{2}}$ and $\boldsymbol{K}_{\mathbf{3}}$ were determined by performing regression analysis for linear equations using datafit-9 software. The parameters/levels considered for experimentation to determine the chip formation and frictional force model coefficients are shown in Table 1 and calculated experimental coefficients are shown in Table 2.

\section{Results and Discussions}

All the following figures (Fig.2), it has very clearly indicated that forces are decreasing with increasing wheel speed. This can be attributed that as the effective chip thickness is decreasing as the wheel speed increasing so as the chip load per grit also decreasing. The tangential force and the normal force in any machining process are governed mainly by the tool rake angle and friction at the chip-tool interface. Large negative rake, lack of sharpness of the grits due to rounding and flattening (by micro fracturing and wear) of the grit tips and relatively much smaller penetration of the cutting points in the work surface are the main causes behind the unusually very large value of normal force as compared to tangential force in grinding.

It has been observed that the contribution of frictional force is much higher than the cutting force. This is due to large negative rake, lack of sharpness of the grits due to rounding and flattening (by micro fracturing and wear) of the grit tips. Figure 2 show the calculated cutting and frictional forces. Figure 3 shows the validation of the total calculated grinding forces (Normal and tangential forces) with the experimental grinding forces.

\section{Conclusions}

1. Physics based grinding process modeling has been established by considering grinding wheel model, microscopic interaction analysis and rubbing.

2. That model demonstrate the feasibility and effectiveness of the methodology mainly the forces components by comparing with the available experimental data.
3. It has been very clearly indicated that the forces are decreasing with increasing wheel speed. This can be attributed that as the effective chip thickness is decreasing as the wheel speed increasing so as the chip load per grit also decreasing.

4. Large negative rake, lack of sharpness of the grits due to rounding and flattening (by micro fracturing and wear) of the grit tips and relatively much smaller penetration of the cutting points in the work surface are the main causes behind the unusually very large value of normal force as compared to tangential force in grinding.

5. All the coefficients were determined by available experimental data, which had captured during grinding bearing steel by single layer brazed cBN wheel.

6. In this research work model, the total grinding forces have been evaluated by incorporating the combined effects of frictional forces and cutting or chip formation forces.

7. It has been observed that the contribution of frictional force is much higher than the cutting force. This is due to large negative rake, lack of sharpness of the grits due to rounding and flattening (by micro fracturing and wear) of the grit tips.

8. The experimental values are happened to be bit larger than theoretical values as it has been depicted in all the graphs. This present research work predicted that there is a plowing force component along with the cutting and frictional force.

\section{References}

Malkin, S. and Guo, C., Grinding technology - Theory and applications of machining with abrasives, New York : Industrial Press, 2008.

Peters, Ir. J., Contributions of CIRP research to industrial problem in grinding, Annals of the CIRP, Vol. 33, 1984, pp. 451-468.

Torrance, A. A., Modeling abrasive wear, Wear, Vol. 258, 2005, pp. 281-293.

Guo, C., et al. , Temperatures and energy partition for grinding with vitrified CBN wheels. Vol. 48, 1999, pp. 247-250.

Konig, W. , loading of the grinding wheel phenomenon and measurement, Annals of the CIRP, Vol. 27, 1978, pp. 217-219.

Lauer-Schmaltz, H. and Konig, Ing. W., Aachen: s.n., Phenomenon of wheel loading mechanisms in grinding, Annals of the CIRP, Vol. 29, 1980, pp. 201-206.

Linke, B., dressing process model for vitrified bonded grinding wheels, Vol. 57, 2008, pp. 345-348. 
Ju, Y., Farris, T. N. and Chandrasekar, S., Theoretical analysis of heat partition and temperatures in grinding, Journal of Tribology, Vol. 120, 1998, pp. 789-794.

Saini, D. P. and Wager, J. G. 1, Local contact deflections and forces in grinding, Annals of the CIRP, Vol. 34, 1985, pp. 281-285.

Wager, J.G. and Saini, D.P. 1, Local contact deflections in grinding - Groups of grains and single grains, Annals of the CIRP, Vol. 35, 1986, pp. 245-248.

Brown, R. H., Saito, K. and Shaw, M. C. 1, Local elastic deflections in grinding, Annals of the CIRP, Vol. 21, 1971, pp. 105-113.
Bhaskar Pal, A.K. Chattopadhyay and A.B. Chattopadhyay "Development and performance evaluation of monolayer brazed cBN grinding wheel on bearing steel", The International Journal of Advanced Manufacturing Technology, Vol 48/9-12 June, 2010, page: 935-944.

Li Lichun, Fu Jizai, A study of grinding force mathematical model, Annals of CIRP, Vol. 29, 1980, pp. 245-249.

M. Younis, M.M. Sadek, T. El Wardani, A new approach to development of a grinding force model, Transactions of ASME, Vol. 109, 1987, pp. 306-313 